Widespread shortfalls in protected area resourcing undermine efforts to conserve biodiversity

Coad, Lauren; Watson, James E. M.; Geldmann, Jonas; Burgess, Neil D.; Leverington, Fiona; Hockings, Marc; Knights, Kathryn; Di Marco, Moreno

Published in:

Frontiers in Ecology and the Environment

DOI:

$10.1002 /$ fee. 2042

Publication date:

2019

Document version

Publisher's PDF, also known as Version of record

Document license:

CC BY

Citation for published version (APA):

Coad, L., Watson, J. E. M., Geldmann, J., Burgess, N. D., Leverington, F., Hockings, M., Knights, K., \& Di

Marco, M. (2019). Widespread shortfalls in protected area resourcing undermine efforts to conserve biodiversity. Frontiers in Ecology and the Environment, 17(5), 259-264. https://doi.org/10.1002/fee.2042 


\title{
Widespread shortfalls in protected area resourcing undermine efforts to conserve biodiversity
}

\author{
Lauren Coad $^{1,2 \star}$, James EM Watson ${ }^{3,4}$, Jonas Geldmann ${ }^{5}$, Neil D Burgess ${ }^{2,6}$, Fiona Leverington ${ }^{3,7}$, Marc Hockings $^{2,3}$, \\ Kathryn Knights ${ }^{7,8}$, and Moreno Di Marco ${ }^{3,9}$
}

Protected areas (PAs) are a key tool in efforts to safeguard biodiversity against increasing anthropogenic threats. As signatories to the 2011-2020 Strategic Plan for Biodiversity, 196 nations pledged support for expansion in the extent of the global PA estate and the quality of PA management. While this has resulted in substantial increases in PA designations, many sites lack the resources needed to guarantee effective biodiversity conservation. Using management reports from 2167 PAs (with an area representing $23 \%$ of the global terrestrial PA estate), we demonstrate that less than a quarter of these PAs report having adequate resources in terms of staffing and budget. Using data on the geographic ranges of the 11,919 terrestrial vertebrate species overlapping our sample of PAs, we estimate that only 4-9\% of terrestrial amphibians, birds, and mammals are sufficiently represented within the existing global PA estate, when only adequately resourced PAs are considered. While continued expansion of the world's PAs is necessary, a shift in emphasis from quantity to quality is critical to effectively respond to the current biodiversity crisis.

Front Ecol Environ 2019; 17(5): 259-264,doi:10.1002/fee.2042

Biodi iodiversity is in steep decline (Tittensor et al. 2014), with monitored vertebrate populations decreasing by almost $60 \%$ on average over the past 40 years (WWF International 2016). Protected areas (PAs) are a major tool in efforts to mitigate this crisis (Watson et al. 2014), and their importance is reflected by the 2011-2020 Strategic Plan for Biodiversity, the key multilateral environmental agreement aimed at halting the decline in biodiversity (UN CBD 2010). Target 11 of the Strategic Plan calls for an expansion of PAs worldwide (hereafter the "global PA estate") to cover $17 \%$ of terrestrial areas and $10 \%$ of marine areas by 2020 , concentrating on well-connected, effectively and equitably managed, and ecologically representative areas of particular importance for biodiversity (UN CBD 2010).

Progress toward PA expansion is typically reported in terms of the growth in overall area designated (Watson et al. 2016). This metric tells an optimistic story: with the global PA estate currently covering about $15 \%$ of the terrestrial surface and $12 \%$ of marine areas within national jurisdiction (UNEPWCMC et al. 2018), nations are on track to achieve the area

${ }^{1}$ Centre for International Forestry Research, Bogor, Indonesia *(lauren.coad@me.com); ${ }^{2}$ UN Environment-World Conservation Monitoring Centre, Cambridge, UK; ${ }^{3}$ School of Earth and Environmental Sciences, The University of Queensland, Brisbane, Australia; ${ }^{4}$ Wildlife Conservation Society, Global Conservation Program, Bronx, NY; ${ }^{5}$ Conservation Science Group, Department of Zoology, University of Cambridge, Cambridge, UK; ${ }^{6}$ Center for Macroecology, Evolution and Climate, Natural History Museum of Denmark, University of Copenhagen, Copenhagen, Denmark; ${ }^{7}$ Protected Area Solutions, Brisbane, Australia; ${ }^{8}$ School of Biosciences, University of Melbourne, Melbourne, Australia; ${ }^{9}$ CSIRO Land \& Water, EcoSciences Precinct, Dutton Park, Australia component of Target 11 by 2020 . However, when the coverage of species and ecosystems are considered, progress toward the Target is less positive, with only $22 \%$ of terrestrial amphibians, $56 \%$ of birds, and $46 \%$ of mammals sufficiently represented in the global PA estate (Butchart et al. 2015).

Establishing more PAs is essential for achieving a comprehensive representation of biodiversity, but adequate representation is insufficient to ensure effective protection for imperiled biodiversity (Di Minin and Toivonen 2015; Di Marco et al. 2016). Well-resourced PAs (that is, those that are sufficiently funded and staffed) are effective tools for conserving biodiversity in both terrestrial and marine environments (Laurance et al. 2012; Gill et al. 2016; Geldmann et al. 2018), but many PAs still have species' populations declining within their boundaries (Craigie et al. 2010; Geldmann et al. 2013). Although many of the world's PAs are thought to lack sufficient resources to effectively manage and mitigate key threats to ecosystems and the biodiversity they support (Di Minin and Toivonen 2015), the degree of under-resourcing remains largely unknown due to a lack of collated, comparable management data.

We used the Global Database on Protected Area Management Effectiveness (GD-PAME; Coad et al. 2015) - the official repository of Protected Area Management Effectiveness (PAME) data agreed upon by Convention on Biological Diversity (CBD) signatory nations (UN CBD 2016) - to conduct the first assessment of progress toward CBD Target 11 in terms of both ecological representation and effective PA man-

This is an open access article under the terms of the Creative Commons Attribution License, which permits use, distribution and reproduction in any medium, provided the original work is properly cited. 


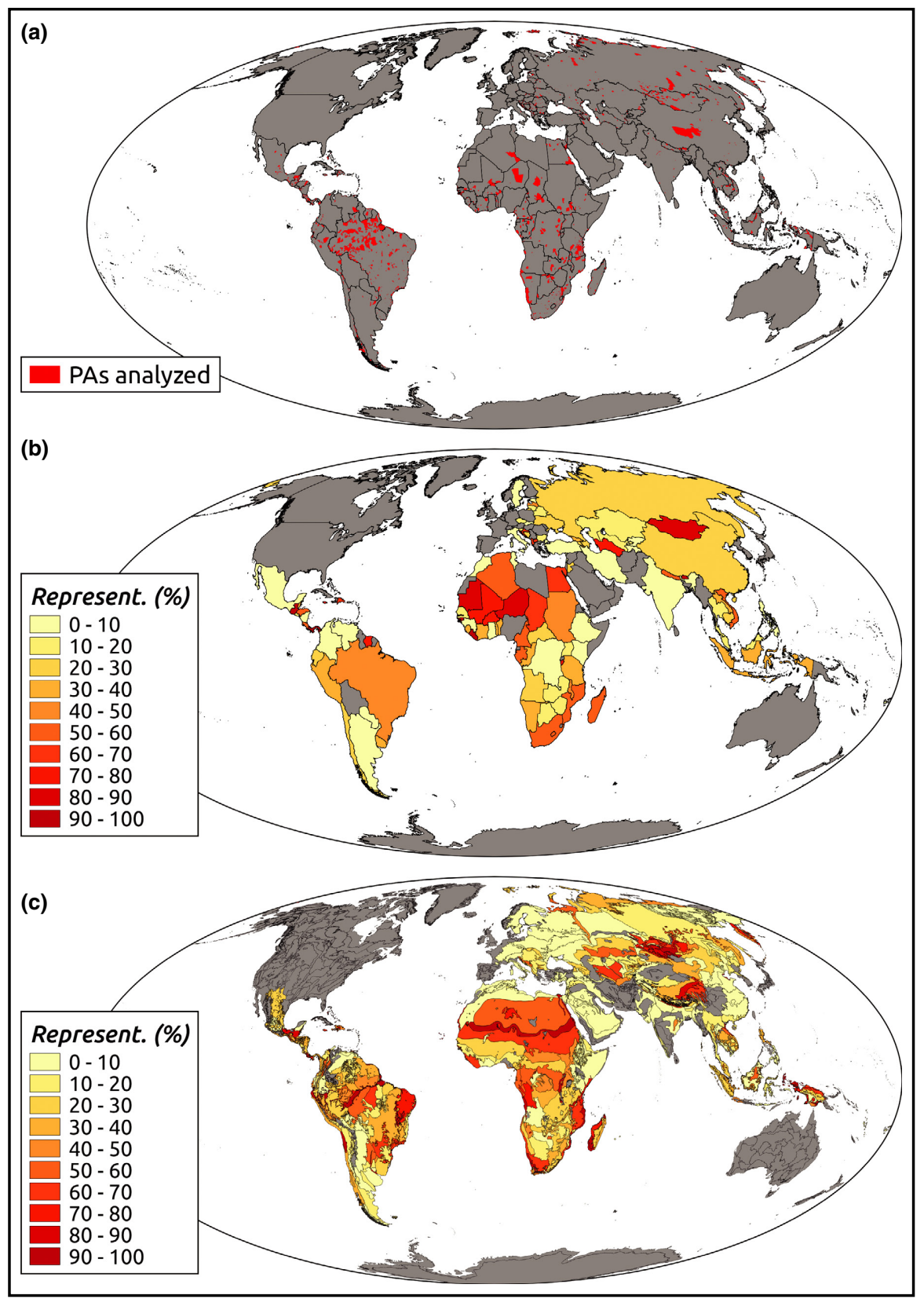

Figure 1. (a) Location of the protected areas (PAs) assessed in the study, and their proportional representation (by area assessed) within the global PA estate by (b) countries and (c) ecoregions.

agement, two key elements of the Target. We calculated the proportion of PAs, by ecological region, that are reported to have adequate staff and budget resources. We then estimated the proportion of terrestrial amphibians, birds, and mammals that are sufficiently represented within the global PA estate, when only adequately resourced PAs are considered.

\section{Methods}

\section{Protected Area Management Effectiveness (PAME) datasets}

PAME evaluation aims to provide an assessment of how well a protected area is being managed: primarily the extent to which management is protecting PA values (eg biodiversity conservation, ecosystem service and cultural service provision) and achieving stated goals and objectives (Hockings et al. 2006). PAME methodologies range from relatively simple questionnaires to more complex approaches; several are specific to individual countries or management agencies, whereas others are applied more widely across the world, especially by international development agencies (Coad et al. 2015). Such evaluations are conducted by PA staff and other stakeholders, and cover different management elements, including planning, inputs, processes, outputs, and outcomes (WebPanel 1; Coad et al. 2015). Although there is a risk of subjective interpretation of scoring levels by managers and stakeholders (Coad et al. 2015), previous studies have indicated that PA managers can provide accurate assessments of PA conditions (Cook et al. 2014), and recent analyses aggregating PAME scores by management element have found significant effects of PA budgets and staffing on conservation outcomes. For example, in the marine realm, fish biomass was 2.9 times and 4.9 times greater in marine PAs (MPAs) that reported adequate staffing and budgets, respectively (Gill et al. 2016), and in the terrestrial realm, PA resources scores were significantly correlated with positive changes in vertebrate abundance (Geldmann et al. 2018).

The GD-PAME contains data from over 18,000 assessments using 21 different PAME methodologies. Four of these methodologies include scores for budget and staff adequacy (WebTable 1), providing assessments for 2167 PAs globally. This sample represents 23\% of the global terrestrial PA estate by area, and approximately half of the world's countries and ecoregions (50.4\% and 58\%, respectively; Figure 1). In being biased toward the Neotropics and Afrotropics, our PA sample is also biased toward areas of high biodiversity (Hillebrand 2004). Our PA sample does not cover North America, Australia, and Western Europe, regions with countries that generally have higher gross domestic product values on average (WebPanel 1) and higher levels of conservation funding (Waldron et al. 2013). Within the countries assessed, our dataset was biased toward larger and older PAs designated for strict biodiversity protection (WebFigures 1-3).

\section{Analyzing PA resource adequacy for ecoregions and species}

For PAs included in our sample, we calculated the proportion of the total PA extent with (1) adequate staff and 
budgets, (2) adequate staff only, (3) adequate budget only, and (4) inadequate staff and budgets. We defined thresholds for adequate and inadequate staffing and budgets, harmonizing scores derived from four PAME methodologies and based on the thresholds set by Gill et al. (2016) using expert consultation (WebTable 2). We then calculated the proportion of total PA extent that was reported to be adequately protected (ie PAs that scored "adequate" for both staff and budget) by individual ecoregion and by biogeographic realm (Olson et al. 2001). To evaluate the proportion of terrestrial species protected within adequately resourced PAs, we identified the 11,919 individual amphibian, bird, and mammal species whose geographic ranges overlapped with the PA boundaries in our sample. For each species, we then calculated the proportion of PA that was adequately resourced (ie adequate scores for staff and budget), out of the assessed PA sample overlapping their range. We then multiplied the proportion of assessed PA that was adequately resourced by the total area of protected range for the species (ie the total PA coverage within each species' range, including assessed and non-assessed PAs; from Butchart et al. 2015). With this we obtained an estimation of the "adequately resourced protected range" for each species. This method provides an estimate of a species' range found within PAs that were reported to have adequate resources to achieve the PAs' objectives, which may focus on ecosystems or species (even if not necessarily on the individual species under consideration; discussed further in WebPanel 1).

To estimate the proportion of species with ranges that were adequately protected, Butchart et al. (2015) defined individual species' "representation targets", based on the approach proposed by Rodrigues et al. (2004). These targets are scaled by species' range size, decreasing from $100 \%$ of species' range protected for species with distributions $<1000 \mathrm{~km}^{2}$ to $10 \%$ of species' range protected for species with distributions $>250,000$ $\mathrm{km}^{2}$, and linearly interpolated on a log-linear scale between these two thresholds. Values were capped at a maximum of 1 million $\mathrm{km}^{2}$ for species with extremely large ranges $(>10$ million $\mathrm{km}^{2}$ ). Using our estimations of "adequately resourced protected range" for each species, and comparing these with the individual species representation targets defined by Butchart et al. (2015), we calculated how many species would meet the PA representation targets outlined above, when only adequately resourced protected range was considered (WebPanel 1; WebFigure 4).

Amphibian and mammal distributions were derived from the International Union for Conservation of Nature (IUCN) Red List (IUCN 2016a); bird distributions were taken from the BirdLife and NatureServe database (BirdLife International and NatureServe 2015); and the locations and spatial extents of the assessed PAs were obtained from the World Database on Protected Areas (UNEP-WCMC and IUCN 2016). Further details about the methods are provided in WebPanel 1.

\section{Results}

We found that only $22.4 \%(n=486)$ of PAs reported adequate resources in terms of both staffing and budgets, which is equivalent to $25.4 \%$ of the total area of PAs that were assessed. In contrast, $46.8 \%(n=1014)$ of PAs reported inadequate resources in both staffing and budgets, which is equivalent to nearly one-half $(47.7 \%)$ of the total area of PAs that were assessed. Where only one aspect was reported to be inadequate, budgets were the more common limiting factor. There were stark differences among terrestrial ecoregions, with PA resourcing being lowest for ecoregions in the Neotropics (where PAs reporting adequate staffing and budget accounted for only $12.5 \%$ of the total assessed PA extent) and highest for ecoregions in the IndoMalay and Palearctic realms (where PA reporting adequate resources for staffing and budget accounted for $39.7 \%$ and $37.4 \%$ of the total assessed PA extent, respectively; Figure 2). The percentage of species achieving target-level representation within adequately resourced PAs was $4 \%$ of amphibians, $8 \%$ of birds, and $9 \%$ of mammals (Figure 3), which are 5.5 times, 7.0 times, and 5.1 times lower, respectively, than the target-level representation reported when the adequacy of PA resourcing is not considered (Butchart et al. 2015).

Our findings highlight two important issues. First, the global PA estate is greatly under-resourced, impeding global 
Adequate+Target $\square$ Target coverage $\quad$ Partial coverage $\square$ No coverage

Mammals

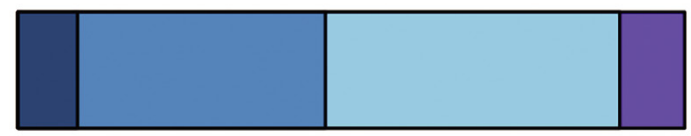

Birds

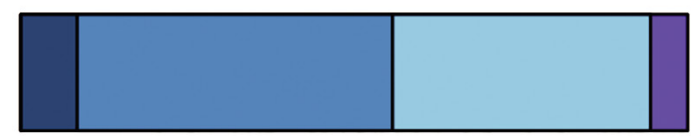

Amphibians

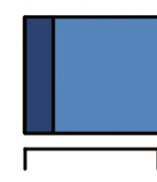

0.0

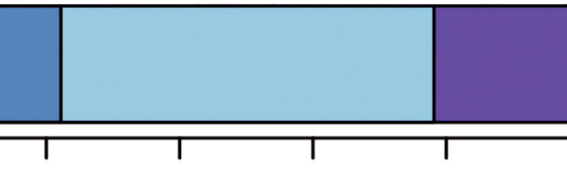

0.2
0.4

0.6

\section{Proportion of species}

Figure 3. The proportion of species that meet representation targets in terms of total PA coverage (from Butchart et al. 2015) and adequately resourced PA coverage (estimated from our data). "No Coverage" represents the proportion of species with less than $2 \%$ of their range protected within PAs; "Partial Coverage" is the proportion of species with a range protection value larger than $2 \%$, but lower than their individual representation target; "Target Coverage" is the proportion of species reaching their representation target coverage; and "Adequate + Target" shows the estimated proportion of species that reach their target coverage within adequately resourced PAs. Note that the three coverage categories are nested within one another, meaning that all species in the category "Adequate + Target" are also part of the category "Target Coverage", which are also part of the category "Partial Coverage". Additional details about the methods are presented in WebPanel 1.

efforts to conserve biodiversity. Second, using simple PA coverage metrics to measure progress toward Target 11, under the assumption that all PAs are effective, is likely to overestimate effective PA coverage by about $400 \%$ and vertebrate species representation by up to $700 \%$.

\section{Discussion}

In the past decade, following the global financial downturn, there is evidence that funding for PAs from both domestic budgets and international aid organizations has been reduced (Caldecott and Jepson 2014), supporting fears that PAs are slipping down national and international priority lists for financial resources (Watson et al. 2014). Between 2011 and 2013, member countries of the Organisation for Economic Co-operation and Development committed <US\$5.6 billion per year to development assistance for biodiversity (UNEPWCMC and IUCN 2016), an amount that falls far short of the estimated US\$76 billion per year required to create and support a well-managed global PA estate (McCarthy et al. 2012). This leaves a funding gap that many countries are unlikely to meet from their domestic budgets. The last attempt to quantify global funding for PAs was carried out 20 years ago (James et al. 1999), and we would therefore urge that an updated review of current spending and shortfalls be conducted to provide an objective assessment of resourcing, identify
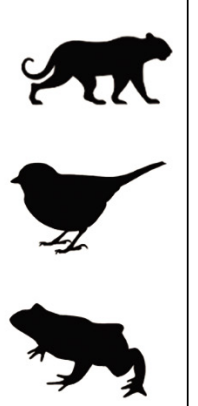

key funding gaps and priorities, and deliver governments and donors with evidence-based funding targets. Alternative funding options for state-managed PAs are now emerging, including trust funds, debt-for-nature swaps, biodiversity offsets, and private-public partnerships (Caldecott and Jepson 2014). While helping to diversify PA funding and forms of governance, these mechanisms- especially those that consist of one-off payments - are unlikely to make up for shortfalls in government support for the costs of ongoing management in the foreseeable future.

In addition, "other effective area-based conservation measures" (OECMs; Laffoley et al. 2017) are gaining increasing recognition as ways to conserve nature in areas outside the PA estate. However, although potentially less dependent on government and international funding, this approach may not have biodiversity protection as a primary aim and may not be established in priority areas for biodiversity conservation (Dudley et al. 2018). Moreover, this does not offset the need for a targeted increase in resources by nations to support existing under-resourced PAs that have been primarily established for the conservation of biodiversity. Multiple forms of protected and conserved areas, funded by diverse approaches and managed by a diverse range of stakeholders (eg communities, indigenous groups, non-governmental organizations, government at national to local levels, the private sector), will be required to deliver Target 11 commitments. In every case, an emphasis on effective, equitable management and the delivery of conservation outcomes will be needed.

We acknowledge that many PAs were created to protect charismatic megafauna, and that while the availability of resources (as reported in the GD-PAME) is likely measured in relation to that objective, PAs with limited resources for charismatic species might still play an important conservation role for biodiversity generally. For instance, the lack of resources to perform specific activities, such as anti-poaching patrols, is unlikely to affect all species in the same way (eg amphibians versus mammals). However, one of the biggest problems that PAs face in the absence of adequate resources is habitat loss and degradation (Jones et al. 2018), and this threat affects all species. This means that a lack of adequate resources, even when measured primarily in relation to charismatic vertebrates, is likely to be relevant for biodiversity in general and may have consequences for thousands of species, as demonstrated by our analyses.

Mounting evidence of the importance of PA resourcing and management in preventing biodiversity declines has led to increased calls for the creation of a restricted set of simple, robust indicators that capture the essence of "effective PA man- 
agement" (Watson et al. 2016; Pringle 2017). These indicators should be used for reporting toward international targets, prioritizing conservation actions, and achieving new PA standards, such as the IUCN's Green List (IUCN 2016b). The correlation between PAME staffing and budget scores and biodiversity outcomes (Gill et al. 2016; Geldmann et al. 2018) suggests that these could be useful management indicators for international reporting on progress toward achieving Target 11 . More outcome-oriented indicators are also needed, so nations can measure and report on true conservation progress. Other important aspects of management - especially governance, equity, and impacts on local communities - are inadequately described with PAME methods (Corrigan et al. 2017; Moreaux et al. 2018), and different metrics for these aspects need to be developed as a priority. Validation of the ability of PAME scores as well as other metrics to accurately reflect different management elements, and analysis of how these metrics correlate with biodiversity outcomes, will be key in developing a robust set of indicators for measuring progress toward PA targets. However, our results suggest that if metrics of management effectiveness are not included in measurements of progress toward Target 11 before 2020, we risk mistakenly reporting global success in achieving Target 11, and sending a false message that sufficient resources are being committed to biodiversity protection. We would therefore support the call for the use of tested metrics of PAME to measure progress toward Target 11 as they become available, while at the same time continuing to develop and refine a set of management indicators up to and beyond 2020 (Chauvenet and Barnes 2016).

Discussions of potential "post-2020" conservation targets for CBD-member countries have already begun (UN CBD 2018). Targeted expansion will still be necessary to capture important areas for biodiversity, as well as those ecosystems that are both substantially threatened and underrepresented. However, whether the global PA estate has the resources to effectively and equitably deliver its intended conservation outcomes must be measured and become a key metric for the CBD parties up to and beyond 2020, to ensure that conservation efforts do not simply create "paper parks" (Di Minin and Toivonen 2015). Despite serious shortfalls in resourcing, PAs are often the last refuge for biodiversity, and have proven potential for preventing catastrophic biodiversity loss (Watson et al. 2014). If nations fail to effectively resource their PA estates, 2020 will be remembered not as the year that biodiversity was safeguarded, but rather as the year that we demonstrated that our commitments to biodiversity are paper-thin.

\section{Acknowledgements}

We thank all of the PA staff and stakeholders who completed PAME assessments, and the organizations, staff and volunteers that worked to compile these assessments, including UN Environment WCMC, the University of Queensland, IUCN SSC-WCPA taskforce on Biodiversity and Protected Areas, WWF, WCS, CEPF and CI, and the GEF and UNDP. LC acknowledges funding support from USAID (Award No AID-BFS-IO-17-00005-0) and JG acknowledges funding support from EUs Horizon 2020 Marie Skłodowska-Curie program (No 676108) and VILLUM FONDEN (VKR023371).

\section{References}

BirdLife International and NatureServe. 2015. Bird species distribution maps of the world. Cambridge, UK: BirdLife International. http://datazone.birdlife.org/species/requestdis. Viewed 15 Nov 2018.

Butchart SHM, Clarke M, Smith RJ, et al. 2015. Shortfalls and solutions for meeting national and global conservation area targets. Conserv Lett 8: 329-37.

Caldecott B and Jepson P. 2014. Towards a framework for protected area asset management. Oxford, UK: Oxford University.

Chauvenet ALM and Barnes M. 2016. Expanding protected areas is not enough. Science 353: 551-52.

Coad L, Leverington F, Knights K, et al. 2015. Measuring impact of protected area management interventions: current and future use of the Global Database of Protected Area Management Effectiveness. Philos T Roy Soc B 370: 20140281.

Cook CN, Carter RWB, and Hockings M. 2014. Measuring the accuracy of management effectiveness evaluations of protected areas. $J$ Environ Manage 139: 164-71.

Corrigan C, Robinson C, Burgess ND, et al. 2017. Global review of social indicators used in protected area management evaluation. Conserv Lett 11: e12397.

Craigie ID, Baillie JEM, Balmford A, et al. 2010. Large mammal population declines in Africa's protected areas. Biol Conserv 143: 2221-28.

Di Marco M, Watson JEM, Venter O, and Possingham HP. 2016. Global biodiversity targets require both sufficiency and efficiency. Conserv Lett 9: 395-97.

Di Minin E and Toivonen T. 2015. Global protected area expansion: creating more than paper parks. BioScience 65: 637-38.

Dudley N, Jonas H, Nelson F, et al. 2018. The essential role of other effective area-based conservation measures in achieving big bold conservation targets. Global Ecol Conserv 15: e00424.

Geldmann J, Barnes M, Coad L, et al. 2013. Effectiveness of terrestrial protected areas in reducing habitat loss and population declines. Biol Conserv 161: 230-38.

Geldmann J, Coad L, Barnes M, et al. 2018. A global analysis of management capacity and ecological outcomes in protected areas. Conserv Lett 11: e12434.

Gill D, Mascia M, Ahmadia G, et al. 2016. Global capacity gaps hinder the ecological performance of marine protected areas. Nature 543: 665-69.

Hillebrand H. 2004. On the generality of the latitudinal diversity gradient. Am Nat 163: 192-211.

Hockings M, Stolton S, Leverington F, et al. 2006. Evaluating effectiveness: a framework for assessing management effectiveness of protected areas. 2nd edn. Gland, Switzerland; Cambridge, UK: IUCN. 
IUCN (International Union for Conservation of Nature). 2016a. The IUCN Red List of Threatened Species, v2016-3. Gland, Switzerland: IUCN.

IUCN (International Union for Conservation of Nature). 2016b. IUCN Green List of Protected and Conserved Areas: user manual, v1.0: the global standard for protected areas in the 21st century. Gland, Switzerland: IUCN.

James AN, Green MJB, and Paine JR. 1999. A global review of protected area budgets and staff. Cambridge, UK: World Conservation Monitoring Centre.

Jones KR, Venter O, Fuller RA, et al. 2018. One-third of global protected land is under intense human pressure. Science 360: 788-91.

Laffoley D, Dudley N, Jonas H, et al. 2017. An introduction to "other effective area-based conservation measures" under Aichi Target 11 of the Convention on Biological Diversity: origin, interpretation and emerging ocean issues. Aquat Conserv 27: 130-37.

Laurance WF, Carolina Useche D, Rendeiro J, et al. 2012. Averting biodiversity collapse in tropical forest protected areas. Nature 489: 290-94.

McCarthy DP, Donald PF, Scharlemann JPW, et al. 2012. Financial costs of meeting global biodiversity conservation targets: current spending and unmet needs. Science 338: 946-49.

Moreaux C, Noelia Z-C, Vansteelant N, et al. 2018. Can existing assessment tools be used to track equity in protected area management under Aichi Target 11? Biol Conserv 224: 242-47.

Olson DM, Dinerstein E, Wikramanayake ED, et al. 2001. Terrestrial ecoregions of the world: a new map of life on Earth. BioScience 51: 933.

Pringle RM. 2017. Upgrading protected areas to conserve wild biodiversity. Nature 546: 91-99.

Rodrigues ASL, Akçakaya HR, Andelman SJ, et al. 2004. Global gap analysis: priority regions for expanding the global protected-area network. BioScience 54: 1092-100.

Tittensor DP, Walpole M, Hill SLL, et al. 2014. Biodiversity targets. Science 346: 241-45.
UN CBD (UN Convention on Biological Diversity). 2010. COP 10 decision X/2. Strategic plan for biodiversity 2011-2020. New York, NY: UN.

UN CBD (UN Convention on Biological Diversity). 2016. COP 13 decision XIII/2. New York, NY: UN.

UN CBD (UN Convention on Biological Diversity). 2018. COP 14 decision XIV/2. New York, NY: UN.

UNEP-WCMC (UN Environment Programme-World Conservation Monitoring Centre) and IUCN (International Union for Conservation of Nature). 2016. The World Database on Protected Areas (WDPA). Cambridge, UK; and Gland, Switzerland: UNEPWCMC and IUCN. www.protectedplanet.net. Viewed 15 Nov 2018.

UNEP-WCNC (UN Environment Programme-World Conservation Monitoring Centre), IUCN (International Union for Conservation of Nature), and NGS (National Geographic Society). 2018. Protected Planet Report 2018. Cambridge, UK; Gland, Switzerland; and Washington, DC: UNEP-WCNC, IUCN, and NGS.

Waldron A, Mooers AO, Miller DC, et al. 2013. Targeting global conservation funding to limit immediate biodiversity declines. $P$ Natl Acad Sci USA 110: 12144-48.

Watson JEM, Dudley N, Segan DB, and Hockings M. 2014. The performance and potential of protected areas. Nature 515: $67-73$.

Watson JEM, Darling ES, Ventner O, et al. 2016. Bolder science needed now for protected areas. Conserv Biol 30: 243-48.

WWF International. 2016. Living planet report 2016: risk and resilience in a new era. Gland, Switzerland: WWF International.

\section{Supporting Information}

Additional, web-only material may be found in the online version of this article at http://onlinelibrary.wiley.com/doi/10. 1002/fee.2042/suppinfo 